J. Martínez-López, J. Rey, J. Dueñas, C. Hidalgo, and J. Benavente - Electrical tomography applied to the detection of subsurface cavities. Journal of Cave and Karst Studies, v. 75, no. 1, p. 28-37. DOI: 10.4311/2011ES0242

\title{
ELECTRICAL TOMOGRAPHY APPLIED TO THE DETECTION OF SUBSURFACE CAVITIES
}

\author{
J. Martínez-López', J. ReY², J. Dueñasª ${ }^{3}$ C. Hidalgo², and J. Benavente ${ }^{4}$
}

\begin{abstract}
We have analyzed the geoelectric response produced by three cavities cut into different geological substrata of granite, phyllite, and sandstone that had previously been characterized by direct methods. We also examined a mining void excavated in granite. In each case, we applied three different geoelectric arrays (Wenner-Schlumberger, Wenner and dipole-dipole) and several inter-electrode spacings. The survey results suggest that electrical resistivity tomography is a viable geophysical tool for the detection and monitoring of mining voids and other subsurface cavities. The results vary depending on a wide range of factors, such as the depth and diameter of the cavity, the multi-electrode array used, the inter-electrode spacing, the geological model, and the density of the data. The resolution capacity of the Wenner- Schlumberger array for the detection of these cavities was greater than that of the Wenner array and slightly better than the dipole-dipole. There is a direct relationship between inter-electrode spacing and diameter of the cavity. In general, we observed a loss of resolution as the distance between the electrodes increased. The most efficient detection was achieved when the inter-electrodes distance was less than or equal to the diameter of the cavity itself. In addition, cavity detection became increasingly less precise with its depth beneath the surface. Cavities with a radius of about $1.5 \mathrm{~m}$ were located by both the WennerSchlumberger method and the dipole-dipole at depths of more than $4.6 \mathrm{~m}$, which means that prospecting can be carried out at depths 3 times the radius of the cavity.
\end{abstract}

\section{INTRODUCTION}

The detection of underground cavities, whether of natural origin such as karstic cavities or of anthropogenic origin such as mining galleries, is of vital importance in land-use planning. In construction projects, and in particular in civil engineering, it is necessary to identify any deep-lying cavities beneath the construction site, as these could cause undesired effects at the surface such as subsidence or complete collapse (De Bruyn and Bell, 2001; Waltham et al., 2005). The use of a suitable geophysical prospecting procedure for the identification and characterization of these underground anomalies renders it unnecessary to use destructive methods, such as drilling boreholes, that are much more expensive and environmentally damaging.

In general, geophysical prospecting involves a number of different techniques that help identify anomalies in the physical and chemical properties of the subsoil, including the propagation of electromagnetic, gravity, acoustic, electrical, or magnetic signals. One of these techniques, electrical resistivity tomography, involves determination of the subsurface distribution of electrical resistivity. This is done by taking a very large number of readings either from the surface or from perforations (Telford et al., 1990; Store et al., 2000). The varying geoelectric response in the area under investigation enables users to obtain $2 \mathrm{D}$ profiles and $3 \mathrm{D}$ images of the distribution of the resistivities under the ground, which makes it a very effective, non-destructive tool for analyzing and characterizing possible discontinu- ities in the subsoil (Sasaki, 1992; Store et al., 2000). The depth range may vary from just a few meters to hundreds of meters in depth. This technique has numerous possible applications when one is faced with various problems in different geological settings (Caputo et al., 2003; Colella et al., 2004). It is increasingly used in environmental studies, hydrogeology (Maillet et al. 2005; Šumanovac, 2006; Martínez et al., 2009), and geotechnics (Naudet et al., 2008), among other fields. This technique has also been used for detection of natural crevice-type caves (van Schoor, 2002; Gutiérrez et al., 2009; Pánek et al., 2010; Gambetta et al., 2011) and in some cases, to locate manmade mining cavities (Maillol et al., 1999; Martínez-López et al., 2007).

The aim of this work was to analyze the resolution of images under different geological conditions and assess the potential for using this technique for locating cavities. Our general objective was to develop a suitable method for the optimum interpretation of resistivity images obtained by electrical tomography so as to be able to characterize cavities in the subsoil. We therefore (i) analyzed the criteria for selecting the best inter-electrode spacings and the most

\footnotetext{
*Corresponding author: jrey@ujaen.es

${ }^{1}$ Dpto. Ingeniería Mecánica y Minera, Escuela Politécnica Superior de Linares, Universidad de Jaén, 23700 Linares (Jaén), Spain

${ }^{2}$ Dpto. de Geología, Escuela Politécnica Superior de Linares, Universidad de Jaén, 23700 Linares (Jaén), Spain

${ }^{3}$ Dpto. Ingeniería Gráfica, Diseño y Proyectos, Escuela Politécnica Superior de Linares, Universidad de Jaén, 23700 Linares (Jaén), Spain

${ }^{4}$ Instituto del Agua, Universidad de Granada, C/Ramón y Cajal 4, 18071 Granada, Spain
} 
suitable multi-electrode array for the characterization of each specific type of cavity, (ii) the capacity of the different techniques to detect the size and shape of the cavity, and (iii) the influence of depth and the nature of the rock substrata on the resolution capacity of each type of array.

We conducted our research at a number of geologically well-documented sites to be able to assess the electrical response afforded by different subsoil structures. The study was mainly carried out in the former mining district of Linares (Jaén Province, southern Spain), where we studied the response to two drainage adits and a cavity formed by a mine chamber over a vein (sites A, B, and D in Fig. 1). Our last site was outside this district in an old mining roadway near Canena, also in the province of Jaén (C in Fig. 1). In cases A, B and C, we conducted a topographic survey (including underground topographic survey, Fig. 2) to chart the underground route of the cavities, their depths, and their dimensions and shapes (Fig. 2). In case D it was not possible to visit the mine, but we have historical information on its geometry.

\section{Methods}

We used electrical resistivity tomography. This is a geoelectric method that analyzes the materials in the subsoil on the basis of their electrical behavior and can provide two and even three-dimensional high-resolution electrical images of the subsurface (Reynolds, 1997; Colella et al., 2004). The method requires numerous electrodes and a system of cables to be installed above the section to be profiled. The distance between the electrodes depends upon the resolution and depth of the particular objectives being sought. In general, the shorter the distance between the electrodes the greater the resolution, and the greater the resolution the greater the depths that it is possible to investigate. Technically, an electrical-resistivity tomography survey can be carried out using different electrode arrays (dipole-dipole, Wenner, Schlumberger) that are spread across the surface above the objective (Loke and Barker, 1996; Reynolds, 1997; Dahlin and Zhou, 2004). Electric current is injected into the ground and the voltage signals are measured. From the configuration of the array it is then possible to calculate the apparent electrical resistivity.

The electrical tomography equipment used in this study is the RESECS model, manufactured by Deutsche Montan Technologie. This is a multi-electrode array with an integrated computer that can handle up to 960 electrodes. The power source is $250 \mathrm{~W}$ and $2.5 \mathrm{~A}$, which generates impulses of $880 \mathrm{~V}$ peak-to-peak. It has a built-in transmitter, receiver, and power supply. Other interesting features include the automatic processing of apparent resistivity and chargeability, real-time resistivity control in $2 \mathrm{D}$ and $3 \mathrm{D}$, control of the current and voltage injection curve, regulation of injection time, built-in $\mathrm{PC}$ and integrated switching processor.
The electrical tomography profiles were interpreted using the RES2DINV resistivity and induced-polarization interpretation software. This calculation program is based on the least-square method with an enforced smoothness constraint, modified with the quasi-Newton optimization technique. The inversion method constructs a model of the subsoil using rectangular prisms and determines the resistivity value for each of them, minimizing the differences between the observed and calculated apparent resistivity values (Loke and Barker, 1996; Loke and Dahlin, 2002).

We collected a total of fourteen electrical tomography profiles at the four sites selected (A, B, C, and D in Fig. 1). At the first three sites, we made a detailed topographic survey of the underground cavities and the positions of the profiles (Fig. 2). Various experiments were conducted at these sites, trying always to ensure that the profile was perpendicular to and centered over the course of the drainage adit. Once we knew the size of the cavity investigated, we used a spacing that was either slightly less than or almost the same as the diameter of the cavity $(1.5 \mathrm{~m})$, or considerably greater $(3 \mathrm{~m})$. We used the Wenner-Schlumberger, dipole-dipole, and Wenner arrays to determine which technique best detected the cavity.

The question of which is the most effective array is a matter of some debate in the literature (see for example the discussions in studies by Zhou et al., 2000; Zhou and Dahlin, 2003; Dahlin and Zhou, 2004; Drahor 2006; Pánek et al., 2010). Some authors consider that the Wenner array is most sensitive to changes in the vertical resistivity of the subsoil (Griffiths and Turnbull, 1985; Griffiths and Barker, 1993), the average reliable depth for investigation being around half that of the spacing (Edwards, 1977). Because it has a small geometric factor, leads to a strong signal even in areas with electromagnetic background noise.

The dipole-dipole array is very sensitive to changes in horizontal resistivity and relatively insensitive to vertical changes. Thus it is useful in the detection of vertical structures such as buried walls, cavities, and contamination plumes. Of the three arrays, the dipole-dipole achieves the greatest average depth of investigation, although its performance is adversely affected in areas with electromagnetic noise.

The Wenner-Schlumberger array is a hybrid between the Wenner and the Schlumberger arrays. According to Pazdirek and Bláha (1996), this array is moderately sensitive to both horizontal and vertical structures. The average investigation depth is greater than with the Wenner array and the intensity of the signal is lower than that of the Wenner, but greater than that of the dipole-dipole.

At sites $\mathrm{A}, \mathrm{B}$, and $\mathrm{C}$ we used eighty electrodes over a length of $120 \mathrm{~m}$ with a spacing of $1.5 \mathrm{~m}$. At site $B$ we repeated the test with an inter-electrode spacing of 3 meters. We used spacings that were equal to or greater than the diameter of the cavity to enable us to prospect for cavities at depths of between 2 and 4 meters with sufficient

Journal of Cave and Karst Studies, April 2013•29 

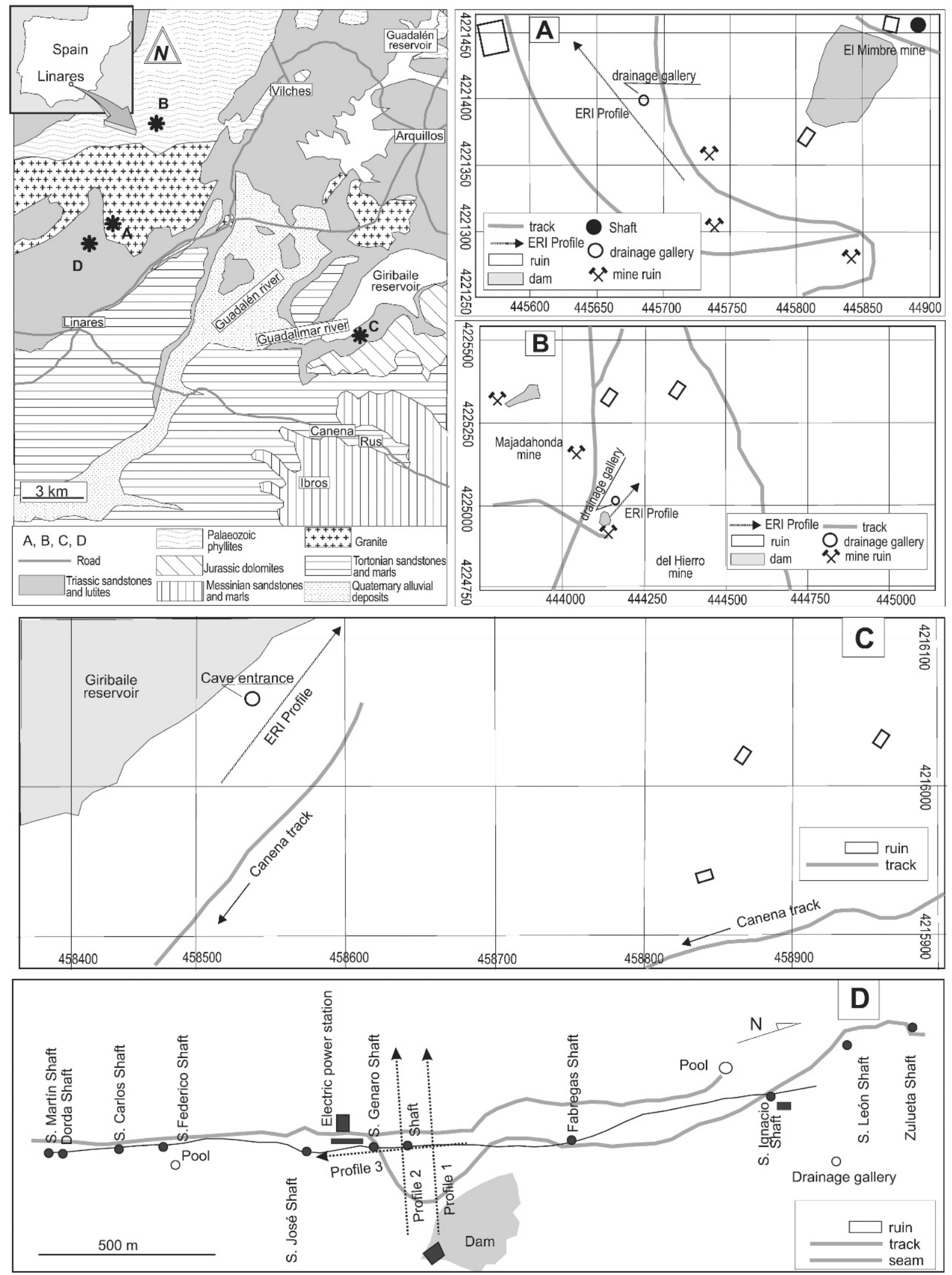

Figure 1. Geographical locations and geological context of the four sites studied, A, B, C, and D. 

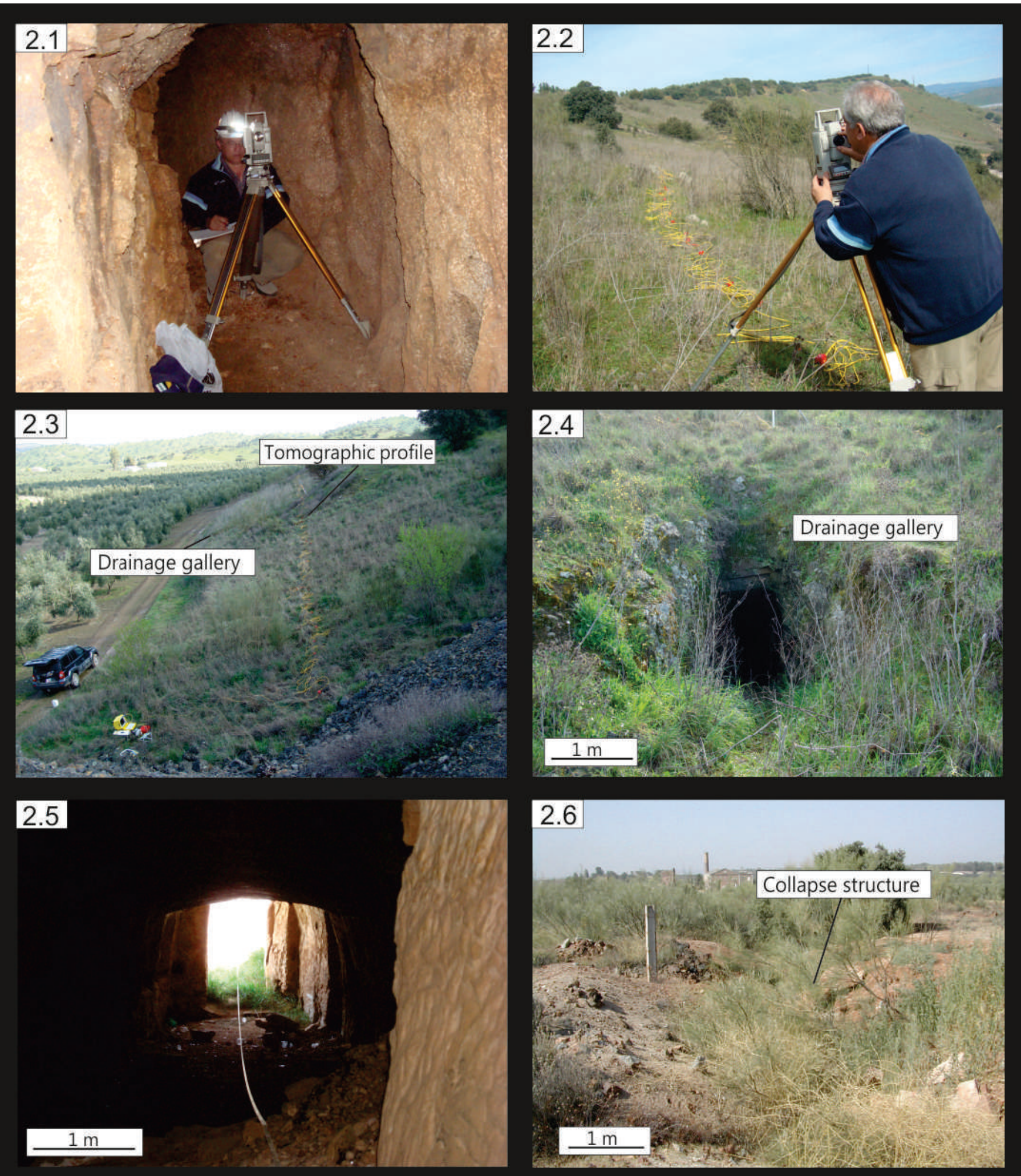

Figure 2. 2.1: Surveying inside the drainage adit at site A, the Mimbre Cavity. 2.2: Topographic surveying at the surface above the tomography profile at site A. 2.3: Route of the electrode array at site B, the Grupo Cobo Cavity, and the entrance to the drainage gallery. 2.4: The entrance to the drainage adit at site B. 2.5: Interior of the mine tunnel that is site $C$, the Canena Cavity. 2.6: Collapse associated with the caved seam at site $D$, the Arrayanes caved seam. 
resolution. At site D, three profiles (Fig. 1D) were made using a Wenner-Schlumberger array with a spacing of $5 \mathrm{~m}$, a value similar to the size of the chambers above the seam. To do this, we used eighty electrodes over a distance of $400 \mathrm{~m}$.

Site A, the Mimbre Cavity, is a drainage adit, currently dry and empty, that was excavated in granite in a northeast-southwest direction. Its average cross-section is $1.60 \mathrm{~m}^{2}$, and it is located at a depth of from 4.6 to $6.4 \mathrm{~m}$. The location of the profiles is in Figure 1A. Figure 3 shows examples of pseudo-sections of real resistivities obtained for each of the arrays we used. With a electrode-spacing of $1.5 \mathrm{~m}$, we took 1,325 measurements of apparent resistivity for the Wenner-Schlumberger array, and a maximum investigation depth of $14.4 \mathrm{~m}$ was reached, with an RMS of 11.4 (Fig. 3A). A total of 1,025 measurements of apparent resistivity were taken for the Wenner array, and a maximum investigation depth of $19.2 \mathrm{~m}$ was reached, with an RMS of 4.2 (Fig. 3B). A total of 2,492 measurements of apparent resistivity were taken for the dipoledipole array, reaching a maximum investigation depth of 11.9 m, with an RMS of 23.3 (Fig. 3C).

The drainage adit at Site B, the Grupo Cobo Cavity, currently dry and empty, is cut into Palaeozoic phyllites, in a northwest-southeast direction. The average cross-section is $1.8 \mathrm{~m}^{2}$, and it is located at a depth of from 4 to $5.8 \mathrm{~m}$. The location of the profiles is in Figure 1B. The lithology and the depth (slightly shallower) are therefore different from the previous experiment. The electrode arrays and spacings were arranged according to the same criteria as at Site A. Figure 4 shows examples of the pseudo-sections of the real resistivities obtained for each of the arrays applied. We took 1,232 readings for the Wenner-Schlumberger array with a spacing of $1.5 \mathrm{~m}$ between each electrode. A depth of $12.7 \mathrm{~m}$ was reached and an RMS of 16.7 was obtained (Fig. 4A). We took 970 readings with the Wenner array; a depth of 15.4 meters was reached and a RMS of 6.7 was obtained (Fig. 4B). We took 2,942 readings with the dipole-dipole array; a depth of $11.9 \mathrm{~m}$ was reached and an RMS of 36.3 was obtained (Fig. 4C). At this site, the Wenner-Schlumberger array was repeated with a spacing of $3 \mathrm{~m}$. We took 225 readings that gave an RMS of 8.2.

Site C, the Canena Cavity, an old mining roadway currently dry and empty was cut into Triassic sandstones in a northwest-southeast direction. The average section is $2.5 \mathrm{~m}^{2}$, and it is located at a depth from 1.8 to $4 \mathrm{~m}$. The lithology is again different, and the depth is the least of our sites. The location of the profiles are in Figure 1C. The electrode arrays and spacings were arranged the same as at Sites A and B. Parts A-C of Figure 5 show the pseudosections of the real resistivities obtained for each of the arrays applied. We took 1,232 readings for the WennerSchlumberger array; a depth of $12.7 \mathrm{~m}$ was reached and an RMS of 42.4 was obtained. We took 970 readings with the Wenner array; a depth of $15.4 \mathrm{~m}$ was reached and an RMS of 47.4 was obtained. We took 2,942 readings with the dipole-dipole array; a depth of $11.9 \mathrm{~m}$ was reached and an RMS of 34.4 was obtained.

At Site D, three profiles were taken near the San Genaro shaft in the Arrayanes caved seam (locations in Fig. 1D). Profile 2, running $113^{\circ}$ to $293^{\circ}$ and perpendicular to the path of the seam, has been selected. Lutites and Triassic sandstones, lying over Palaeozoic granite, crop out at the surface. Although in this case, we were unable to carry out a topographic survey, the exact position and morphology of the cavity produced after mining the seam is known. This cavity is up to $5 \mathrm{~m}$ thick and, due to the collapse of the structure, is partially filled at the top with lutites. The profiles had a interelectrode spacing of $5 \mathrm{~m}$ in a Wenner-Schlumberger array. The total length was $400 \mathrm{~m}$ and it contained eighty electrodes, reaching an investigation depth of $75 \mathrm{~m}$. We took 1,419 readings and obtained an RMS of 8.3 (Fig. 5D).

\section{RESUlTS}

From a geophysical point of view, the geologic structure at Site A behaves like a two-layer model with all three arrays. It has a 2 to $4 \mathrm{~m}$ thick surface layer that shows low resistivity values $(<300 \mathrm{ohm}-\mathrm{m})$ that consists of altered granite with varying degrees of water saturation. Below this, there is a more resistive mass that is composed of unaltered granite.

Using a spacing of $1.5 \mathrm{~m}$, similar to the diameter of the cavity, with the Wenner-Schlumberger configuration we detected a resistivity feature that coincided with the position of the cavity (Fig. 3A). The position of the structure could not be defined with the Wenner method because low resistivity values were obtained compared to the readings in the previous experiment (Fig. 3B). With the dipole-dipole array the cavity was located but the RMS numbers were higher (Fig. 3C).

At Site $\mathrm{B}$ the geologic structure behaves like a threelayer model. There is a 1 to $2 \mathrm{~m}$ thick surface layer with high resistivity values ( $>300 \mathrm{ohm}-\mathrm{m}$ ) that probably consists of breccia and the remains of an old spoil-heap. Beneath this, there is a layer of altered phyllites. The irregular distribution of areas with varying degrees of alteration, fractures, and water saturation may explain the large oscillations in the resistivity values between 20 and 200. Below this, is another layer that has the highest resistivity values. These values (up to 1200 ohm-m) coincide with the least altered phyllites.

Using the Wenner-Schlumberger array with a spacing of $1.5 \mathrm{~m}$, similar to the diameter of the cavity, we detected an increase in resistivity in an area that coincided with the position of the cavity. Two additional peaks in resistivity were observed at a depth of about $6 \mathrm{~m}$ (Fig. 4A). These may correspond to two service galleries near the seam. The dipole-dipole array appeared to detect the same structure with high resistivity values, although its morphology was less precise (Fig. 4C). The Wenner array detected the structures but the resolution was lower (Fig. 4B). 


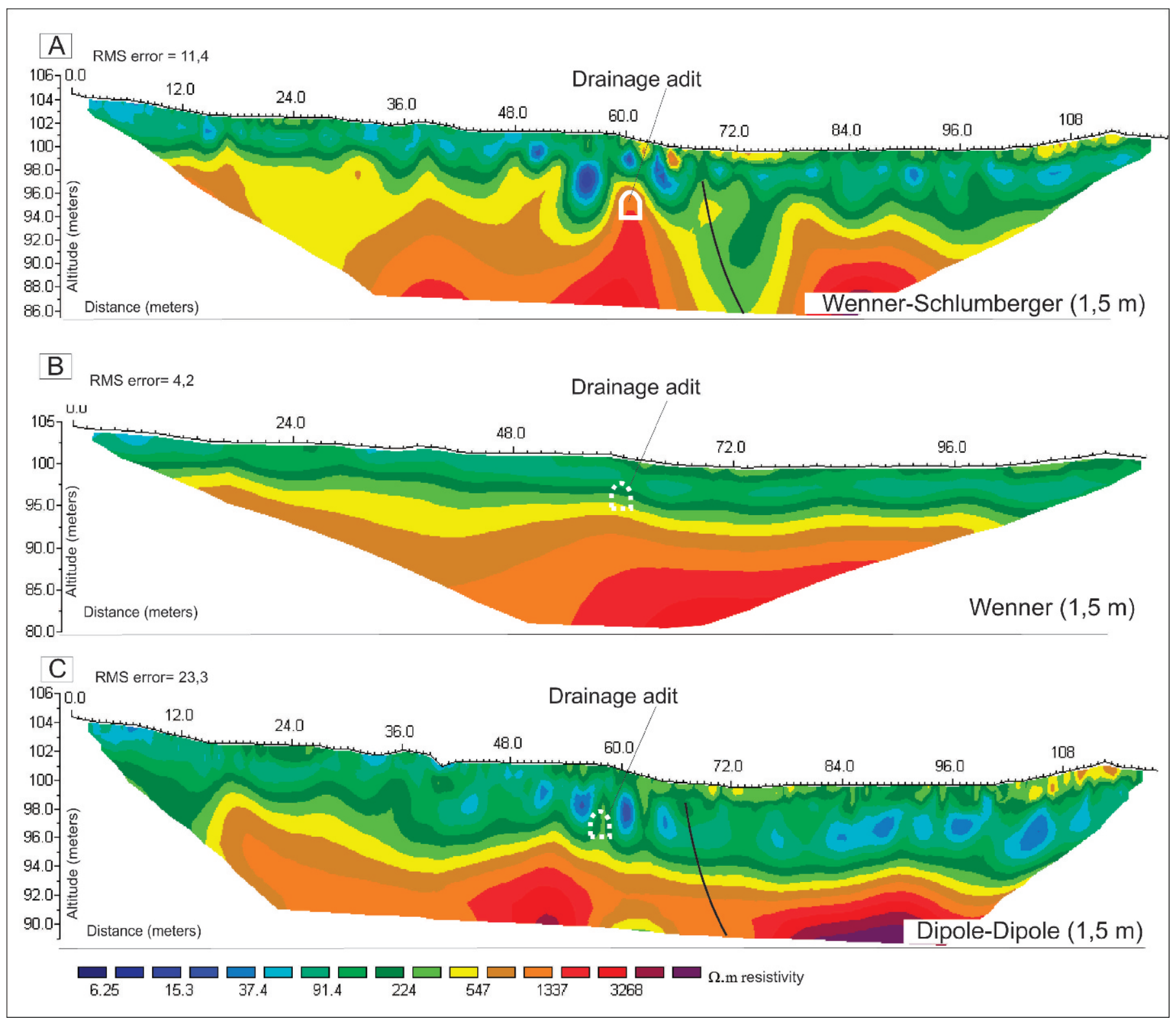

Figure 3. Electrical resistivity tomography profiles obtained at the site $\mathrm{A}$ in granite, using the arrays and electrode spacing indicated. Note that the vertical scales are all different.

A loss of resolution was noted as the spacing between the electrodes increased. As a result, with a spacing of $3 \mathrm{~m}$ (double the diameter of the cavity) the gallery could not be defined (Fig. 4D).

In the Site $\mathrm{C}$ profiles with all three arrays, the geologic structure of this sector behaves like a two-layer model. In addition to a discontinuous surface level of breccia that shows high resistivities of up to $2,000 \mathrm{ohm}-\mathrm{m}$, two distinct units can be seen. There is a 1 to $10 \mathrm{~m}$ thick surface layer that shows low resistivity values $(<350)$ and is probably composed of calcarenites. Underneath this layer, a more resistive facies appears, with values ranging from 1,000 to $2,500 \mathrm{ohm}-\mathrm{m}$, that would appear to be a siliceous conglomerate. The contact between the two units is affected by fractures.
With the Wenner-Schlumberger array, the anomaly was clearly indicated by high resistivity values (Fig. 5A). With the dipole-dipole array, the gallery was located as an area with medium resistivity levels (Fig. 5C). The gallery could not be detected with the Wenner array (Fig. 5B).

A two-layer geophysical model can also be applied to Site D, the caved seam. There is a surface level with low resistivity $(<250)$ that would appear to be formed by either Triassic lutite or highly altered granite. Beneath this layer, there is an increase in resistivity that would appear to coincide with somewhat less altered granite. Using the Wenner-Schlumberger array with a spacing of $5 \mathrm{~m}$, similar to the diameter of the cavity, we detected a very well defined maximum resistivity that corresponds to a mined 


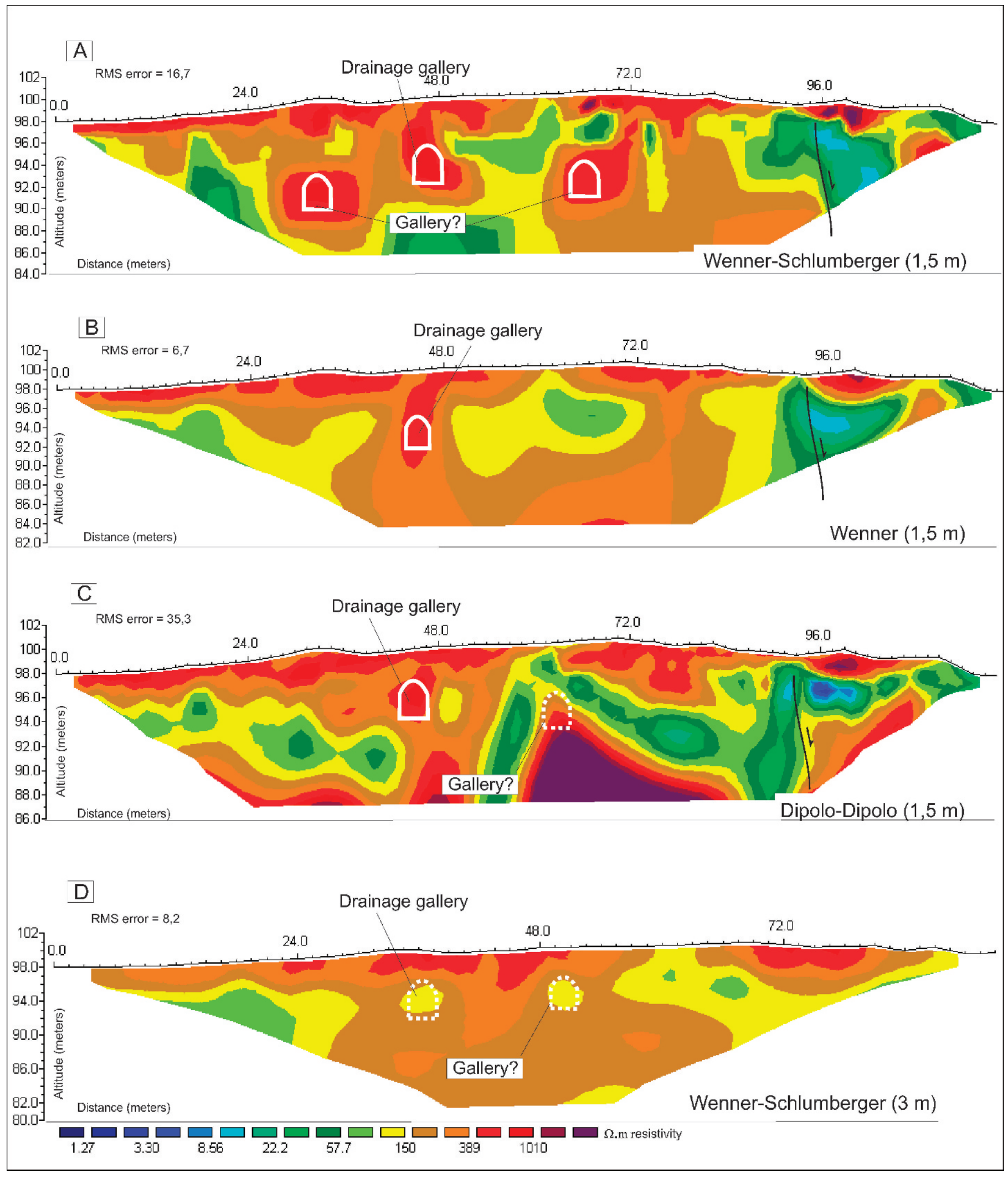

Figure 4. Electrical resistivity tomography profiles obtained at site B in phyllite, using the arrays and electrode spacing indicated. Note that the vertical scales are all different and the horizontal scale in part $D$ is different. 


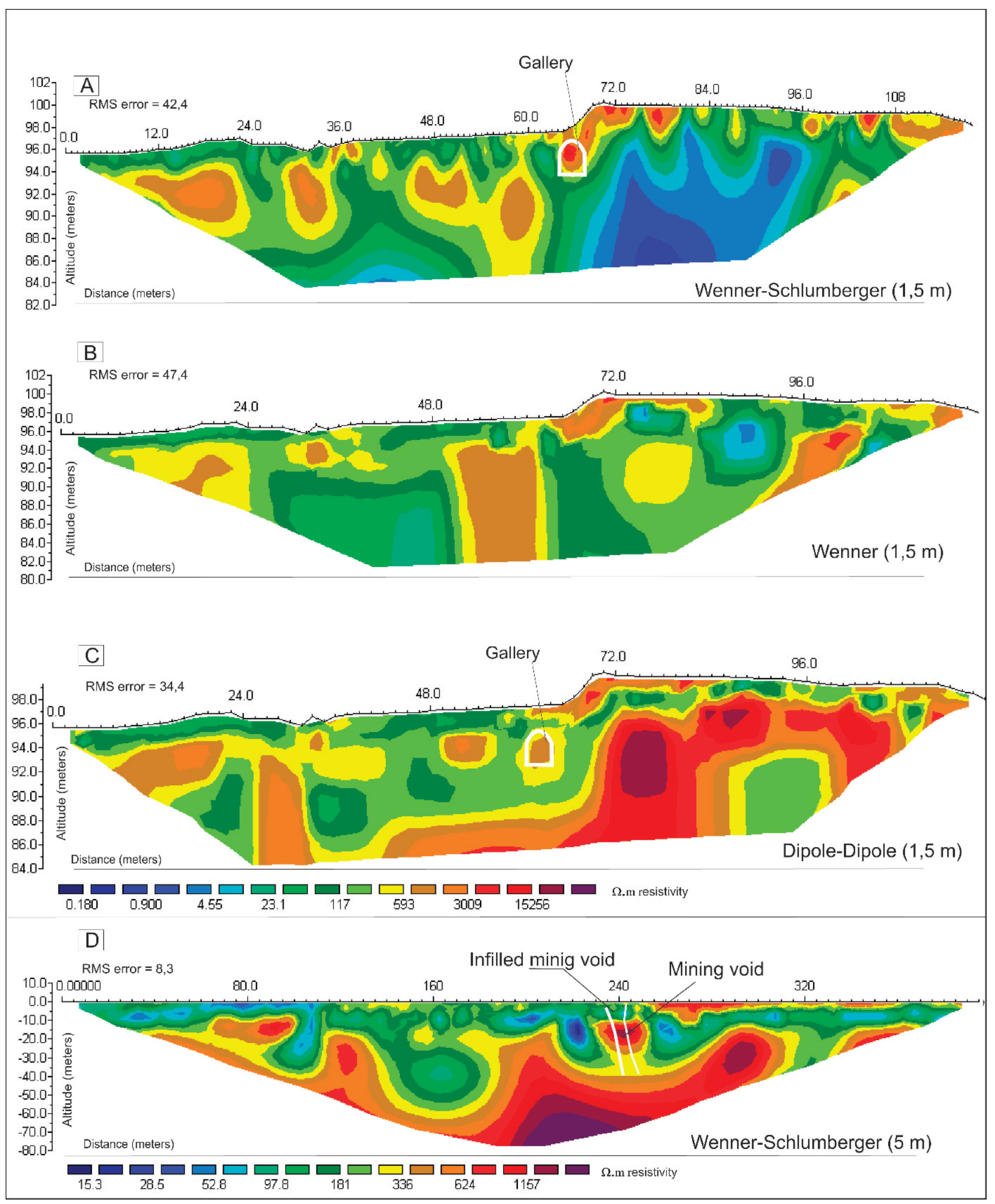

Figure 5. A-C, electrical resistivity tomography profiles obtained at site $\mathrm{C}$ in sandstone, using the array and electrode spacing indicated. Note that the vertical scales are all different. Part D, profile 2 at site D, the collapsed mine chamber. 
chamber orientated along the previous path of the seam (Fig. 5D). The cavity shows two different types of behavior. In the upper part, the collapse of the protective surface layer has resulted in a partial infill of lutites, so that in the sector closest to the surface the caved seam behaves like a conductor, with values ranging from 60 to $160 \mathrm{ohm}$ m. At greater depths, the empty chamber shows higher resistivity, with values ranging from 600 to $1500 \mathrm{ohm}-\mathrm{m}$.

\section{Discussion And Conclusions}

Electrical resistivity tomography is a geophysical prospecting technique that can detect cavities in the subsoil. We describe here several cases in which this prospecting method has been used to detect cavities associated with past mining work in the Linares mining district and another cavity near Canena (Jaén Province, southern Spain). In all these examples, the position, shape, and characteristics of the structures were well known and documented, and the aim of our electrical tomography experiments was to test the efficacy of the technique itself.

Our results varied depending upon a multitude of physical factors, such as the depth and diameter of the cavity and the local geology, and the method factors, such as the array configuration, the inter-electrode spacing, and the density of data. In addition, when the cavity was empty, there was an anomaly with a steep gradient and very high resistivity values as the air filling the cavity is dielectric. When the cavities were filled with fine, loose material, usually saturated in water, the electrical resistance was lower, as both water and clay are good conductors of electric current (see Pánek et al, 2010). In this situation, electrical tomography shows an anomaly with a low resistivity value, as near the surface in Figure 5D.

Of the three arrays types we used, the WennerSchlumberger array offered the highest resolution in the three cases studied of cavities excavated in a variety of different lithologies. This array also identified the presence of the mine chamber. The results obtained with the dipoledipole array were positive in the case of the phyllites (a resistive rock) and negative in the case of sandstones (resistive) and altered granites (low resistivity). The Wenner array produced poorer results with all three cavities. The quality of the results was correlated with the RMS numbers, which were always lower and more stable with Wenner-Schlumberger and higher and more unstable with dipole-dipole and Wenner.

There was a maximum inter-electrode spacing above which the arrays we used could not detect the cavities. The quality of cavity detection was at its best when the distance between the electrodes was less than or equal to the diameter of the cavity (compare the Fig. 4A and Fig. 4D). When the spacing was greater than the diameter of the cavity, at best, only vague traces of the cavities could be identified, but these profiles did not include identifying images.
As far as the depth of the cavity was concerned, those that were closest to the surface could be located more efficiently. In general, cavity detection was less precise with an increase in depth. Using the Wenner-Schlumberger method, and to a lesser extent the dipole-dipole, we located cavities with a radius of about $1.5 \mathrm{~m}$ at depths of over $4.6 \mathrm{~m}$, which means that prospecting can be carried out at depths of 3 times the radius of the cavity.

\section{AcKnowledgements}

This research was financed by the Spanish Ministry of Science and Innovation (Project CGL2009-12396) and by the Government of Junta de Andalucía (Project RNM 05959). The authors thank two anonymous reviewers for their critical comments that significantly improved the manuscript.

\section{REFERENCES}

Caputo, R., Piscitelli, S., Oliveto, A., Rizzo, E., and Lapenna, V., 2003, The use of electrical resistivity tomographies in active tectonics: Examples from the Tyrnavos Basin, Greece: Journal of Geodynamics, v. 36, p. 19-35. doi:10.1016/S0264-3707(03)00036-X.

Colella, A., Lapenna, V., and Rizzo, E., 2004, High-resolution imaging of the High Agri Valley Basin (Southern Italy) with electrical resistivity tomography: Tectonophysics, v. 386, p. 29-40. doi:10.1016/j.tecto. 2004.03.017.

Dahlin, T., and Zhou, Bing, 2004, A numerical comparison of 2D resistivity imaging with 10 electrode arrays: Geophysical Prospecting, v. 52, p. 379-398. doi:10.1111/j.1365-2478.2004.00423.x.

De Bruyn, I.A., and Bell, F.G., 2001, The occurrence of sinkholes and subsidence depressions in the far West Rand and Gauteng Province, South Africa, and their engineering implications: Environmental and Engineering Geoscience, v. 7, p. 281-295. doi:10.2113/gseegeosci. 7.3.281.

Drahor, M.G., 2006, Integrated geophysical studies in the upper part of Sardis archaeological site, Turkey: Journal of Applied Geophysics, v. 59, p. 205-223. 10.1016/j.jappgeo.2005.10.008.

Edwards, L.S., 1977, A modified pseudosection for resistivity and induced-polarization: Geophysics, v. 42, p. 1020-1036. doi:10.1190/ 1.1440762 .

Gambetta, M., Armadillo, E., Carmisciano, C., Stefanelli, P., Cocchi, L., and Tontini, F.C., 2011, Determining geophysical properties of a near-surface cave through integrated microgravity vertical gradient and electrical resistivity tomography measurements: Journal of Cave and Karst Studies, v. 73, p. 11-15. doi:10.4311/jcks2009ex0091.

Griffiths, D.H., and Barker, R.D., 1993, Two-dimensional resistivity imaging and modelling in areas of complex geology: Journal of Applied Geophysics, v. 29, p. 211-226. doi:10.1016/0926-9851(93) 90005-J.

Griffiths, D.H., and Turnbull, J., 1985, A multi-electrode array for resistivity surveying: First Break, v. 3, no. 7, p. 16-20.

Gutiérrez, F., Galve, J.P., Lucha, P., Bonachea, J., Jordá, L., and Jordá, R., 2009, Investigation of a large collapse sinkhole affecting a multistorey building by means of geophysics and the trenching technique (Zaragoza city, NE Spain) Environmental Geology, v. 58, p. 11071122. doi:10.1007/s00254-008-1590-8.

Loke, M.H., and Barker, R.D., 1996, Rapid least-squares inversion of apparent resistivity pseudosections by a quasi-Newton method: Geophysical Prospecting: v. 44, p. 131-152. doi:10.1111/j.1365-2478. 1996.tb00142.x.

Loke, M.H., and Dahlin, T., 2002, A comparison of the Gauss-Newton and quasi-Newton methods in resistivity imaging inversion: Journal of Applied Geophysics, v. 49, p. 149-162. doi:10.1016/S0926-9851(01) 00106-9.

Maillet, G.M., Rizzo, E., Revil, A., and Vella, C., 2005, High resolution electrical resistivity tomography (ERT) in a transition zone environment: 
Application for detailed internal architecture and infilling processes study of a Rhône River paleo-channel: Marine Geophysical Research, v. 26, p. 317-328. doi:10.1007/s11001-005-3726-5.

Maillol, J.M., Seguin, M.-K., Gupta, O.P., Akhauri, H.M., and Sen, N., 1999, Electrical resistivity tomography survey for delineating uncharted mine galleries in West Bengal, India: Geophysical Prospecting: v. 47, p. 103-116. doi:10.1046/j.1365-2478.1999.00126.x.

Martínez, J., Benavente, J., García-Aróstegui, J.L., Hidalgo, M.C., and Rey, J., 2009, Contribution of electrical resistivity tomography to the study of detrital aquifers affected by seawater intrusion-extrusion effects: The River Vélez delta (Vélez-Málaga, southern Spain): Engineering Geology, v. 108, p. 161-168. doi:10.1016/j.enggeo.2009. 07.004 .

Martínez-López, J., Rey, J., Sandoval, S., and Rodríguez, M., 2007, La tomografía eléctrica: una herramienta para la detección de huecos mineros (concesión de Arrayanes, Linares-Jaén): Geogaceta, v. 42, p. 43-46.

Naudet, V., Lazzari, M., Perrone, A., Loperte, A., Piscitelli, S., and Lapenna, V., 2008, Integrated geophysical and geomorphological approach to investigate the snowmelt-triggered landslide of Bosco Piccolo village (Basilicata, southern Italy): Engineering Geology, v. 98, p. 156-167. doi:10.1016/j.enggeo.2008.02.008.

Pánek, T., Margielewski, W., Tábořík, P., Urban, J., Hradecký, J., and Szura, C., 2010, Gravitationally induced caves and other discontinuities detected by 2D electrical resistivity tomography: Case studies from the Polish Flysch Carpathians: Geomorphology, v. 123, p. 165-180. doi:10.1016/j.geomorph.2010.07.008.

Pazdîrek, O., and Bláha, V., 1996, Examples of resistivity imaging using ME-100 resistivity field acquisition system. EAGE $58^{\text {th }}$ Conference and Technical Exhibition Extended Abstracts, Amsterdam, P050.
Reynolds, J.M., 1997, An Introduction to Applied and Environmental Geophysics: Chichester, England, John Wiley \& Sons, 796 p.

Sasaki, Y., 1992, Resolution of resistivity tomography inferred from numerical simulation: Geophysical Prospecting, v. 40, p. 453-463. doi:10.1111/j.1365-2478.1992.tb00536.x.

Šumanovac, F., 2006, Mapping of thin sandy aquifers by using high resolution reflection seismics and 2-D electrical tomography: Journal of Applied Geophysics, v. 58, p. 345-346. doi:10.1016/j.jappgeo.2005. 06.005 .

Store, H., Storz, W., and Jacobs, F., 2000, Electrical resistivity tomography to investigate geological structures of earth's upper crust: Geophysical Prospecting, v. 48, p. 455-471. doi:10.1046/j.13652478.2000.00196.x.

Telford, W.M., Geldart, L.P., and Sheriff, R.E., 1990, Applied Geophysics, second edition: Cambridge, Cambridge University Press, $770 \mathrm{p}$.

van Schoor, M., 2002, Detection of sinkholes using 2D electrical resistivity imaging: Journal of Applied Geophysics, v. 50, p. 393-399. doi:10. 1016/S0926-9851(02)00166-0.

Waltham, T., Bell, F., and Culshaw, M., 2005, Sinkholes and Subsidence: Karst and Cavernous Rocks in Engineering and Construction: Chichester, England, Springer, $382 \mathrm{p}$.

Zhou, Wanfang, Beck, B.F., and Stephenson, J.B., 2000, Reliability of dipole-dipole electrical resistivity tomography for defining depth to bedrock in covered karst terranes: Environmental Geology, v. 39, p. 760-766. doi:10.1007/s002540050491.

Zhou, Bing, and Dahlin, T., 2003, Properties and effects of measurements errors on 2D resistivity imaging: Near Surface Geophysics, v. 1, p. 105-117. doi:10.3997/1873-0604.2003001. 